\title{
БАЛАНС РАСТИТЕЛЬНЫХ ОСТАТКОВ СЕЛЬСКОХОЗЯЙСТВЕННЫХ КУЛЬТУР В УЧХОЗЕ «МИНДЕРЛИНСКОЕ»
}

\author{
E.I. Voloshin, V.K. Ivchenko
}

\section{THE BALANCE OF CROP RESIDUES ON TRAINING FARM "MINDERLINSKOE"}

Волошин Евгений Иванович - д-р с.-х. наук, проф. каф. общего земледелия и защиты растений Красноярского государственного аграрного университета, г. Красноярск.

E-mail: EV.Volochin@ yandex.ru

Ивченко Владимир Кузьмич - д-р с.-х. наук, проф. каф. общего земледелия и защиты растений Красноярского государственного аграрного университета, г. Красноярск.

E-mail: v.f.ivchenko@mail.ru

Рациональное использование растительных остатков в земледелии является одним из фракторов сохранения и повышения плодородия почв. Использование растительных остатков сельскохозяйственных культур на удобрение способствует увеличению в почвах содержания гумуса и питательных веществ. Анализ урожайности сельскохозяйственных культур в учебно-опьтнном хозяйстве «Миндерлинское» за годы наблюдений свидетельствует, что за последние три года этот показатель существенно вырос у зерновых культур. Для этих же культур характерно и максимальное количество поступающих в почву растительных остатков, которое колебалось в среднем за три года от 6,40 m/га (ячмень) до 7,58 m/га (овес). Это в 2,2 раза больше, чем nоступает в почву растительных остатков, в сравнении с однолетними и многолетними травами, у которых надземная масса полностью отчуждается с поля. Минимальное количество растительных остатков постуnаem в почву после выращивания картофреля, сои и многолетних злаковых трав. Максимальным количеством поступающих с растительными остатками в почву питательных веществ характеризуются посевы зерновых культур по сравнению с другими культурами. В среднем же по хозяйству с растительными остатками полевых культур в почву поступаem 29,9 кг/га азота, фоосфора и калия. В то же
Voloshin Evgeny Ivanovich - Dr. Agr. Sci., Prof., Chair of General Agriculture and Plants Protection, Krasnoyarsk State Agrarian University, Krasnoyarsk.

E-mail: EV.Volochin@yandex.ru

Ivchenko Vladimir Kuzmich - Dr. Agr. Sci., Prof., Head, Chair of General Agriculture and Plants Protection, Krasnoyarsk State Agrarian University, Krasnoyarsk.

E-mail: v.f.ivchenko@mail.ru

время различные сельскохозяйственные культуры выносят неодинаковое количество питательных веществ, которое в значительной степени зависит от иелого ряда фракторов. Самым высоким выносом макроэлементов характеризуются зерновые культуры, минимальным - соя, картофель, однолетние травы. В среднем по учхозу «Миндерлинское» компенсация выноса урожаями культур за счет внесения в почву растительных остатков в качестве органических удобрений для азота составляет $32,6 \%$, фоосфора - 14,0 и калия $37,8 \%$.

Ключевые слова: растительные остатки, урожайность, гумифиикация, плодородие, вынос, компенсация, баланс питательных веществ.

Rational plant residues using in agriculture is one of the factors of protection and increasing soil fertility. Using plant residues of crops for fertilizer increases the content of humus and nutrients in soils. The analysis of crop yields on"Minderlinskoe" training and experimental farm over the years of observation indicates that over three years this indicator has grown significantly in crops. For the same cultures the maximum quantity of vegetable residues coming to the soil fluctuating on average in three years from 6.40 t/hectare (barley) to 7.58 thectare (oats) is typical. It is 2.2 times more, than vegetable remains coming into the soil in 
comparison with annual and perennial herbs at which elevated weight is completely alienated from the field. The minimum quantity of vegetable remains comes to the soil after cultivation of potatoes, soy and perennial cereal herbs. The crops of cereals are characterized by the maximum quantity of the nutrients coming with vegetable remains to the soil in comparison with other cultures. On average $29.9 \mathrm{~kg} / \mathrm{hectare}$ of nitrogen, phosphorus and potassium come to the farm's soil with vegetable remains of field cultures. At the same time various crops take out unequal amount of nutrients substantially depending on a number of factors. Grain crops are characterized by the highest removal of macronutrients, soy, potatoes and annual herbs by minimum. On average, on 'Minderlinskoe' training farm, the compensation for crop removal due to plant residues being added to the soil as organic fertilizers for nitrogen is $32.6 \%$, phosphorus $14.0 \%$, and potassium $37.8 \%$.

Keywords: plant residues, productivity, humification, fertility, nutrient removal, compensation, balance of nutrients.

Введение. В биологизации агротехнологий для оптимизации плодородия почв и повышения продуктивности земледелия важная роль отводится рациональному использованию растительных остатков и побочной продукции разных сельскохозяйственных культур. В агроценозах растительные остатки оказывают многостороннее прямое и косвенное влияние на фризические, химические, биологические свойства почвы, ее воздушный, температурный и пищевой режимы [8]. Под влиянием растительных остатков в почвах происходит увеличение содержания общего, мобильного и водорастворимого гумуса. Увеличение содержания гумуса в пахотном слое связано с характером поступления, распределения и разложения растительных остатков. Разложение органического вещества наиболее интенсивно идет в верхнем слое почв, с глубиной процессы минерализации затухают. Роль культур в накоплении гумуса определяется структурой севооборота. Культуры сплошного сева более положительно влияют на накопление гумуса в почве, чем пропашные, под которыми наблюдается преобладание процессов минерализации над синтезом органического вещества [5].

Растительные остатки содержат большое количество элементов питания, которые ис- пользуют последующие культуры севооборота. Темпы поступления питательных веществ в почву зависят от биологических особенностей растений, региональных почвенноклиматических условий, типов севооборотов, уровня агротехники и величины урожаев сельскохозяйственных культур [3]. При существующих технологиях возделывания полевых культур отмечается диспропорция между количеством синтезируемой биомассы растений и поступающей в почву вследствие отчуждения ее части с урожаем.

Растительные остатки оказывают положительное влияние на урожайность культур не только как источник элементов минерального питания. Как и любое органическое удобрение, они активизируют почвенную микрофрлору и положительно воздействуют на агрофизические свойства и водный режим почвы. После их внесения уменьшается плотность почвы, увеличивается ее пористость, коэфффициент структурности и количество водопрочных агрегатов. В адаптивно-ландшафтных системах земледелия растительные остатки являются одним из факторов предотвращения эрозии почв [4].

В связи с сокращением применения навоза в региональном земледелии необходимо увеличить объемы использования растительных остатков сельскохозяйственных культур в качестве органических удобрений [2]. Особенности накопления и химический состав растительных остатков следует учитывать при планировании системы земледелия и расчете доз удобрений в каждом хозяйстве региона. Применение растительных остатков полевых культур на удобрение является одним из наиболее доступных и экономически эффрективных способов оптимизации плодородия почв и улучшения экологической ситуации в агроценозах.

Цель исследований. Изучение баланса растительных остатков сельскохозяйственных культур в учхозе «Миндерлинское» ФГБОУ ВО «Красноярский государственный аграрный университет».

Объекты исследований. Учхоз «Миндерлинское» находится в Красноярской лесостепной зоне и специализируется на производстве растениеводческой и животноводческой продукции.

Климат на территории хозяйства характеризуется резкой континентальностью. Среднемноголетняя сумма осадков составляет 365 мм. Ос- 
новная масса осадков выпадает в летний период. Они часто имеют ливневый характер. На долю зимних осадков приходится 15-25\% годового количества. Среднегодовая температура ниже $0{ }^{\circ} \mathrm{C}$. Зима суровая и продолжительная (180-200 дней). Мощность снежного покрова в среднем не превышает 25-30 см. Глубина промерзания почвы на открытых и повышенных элементах рельедра может достигать до 1,5-2,0 метров. Продолжительность вегетационного периода растений колеблется от 140 до 160 дней. Среднемноголетняя сумма активных температур выше $10^{\circ} \mathrm{C}$ варьирует от 1550 до $1650^{\circ} \mathrm{C}$.

B пашне преобладают черноземы, серые лесные и лугово-черноземные почвы. Особенностью почвенного покрова в хозяйстве является значительная комплексность, укороченность аккумулятивного горизонта и тяжелый гранулометрический состав почв. Неодинаковые условия почвообразования оказали влияние на плодородие почв, эффективность удобрений и урожайность сельскохозяйственных культур. Среднее содержание гумуса в 0-20 см слое почв колеблется от 5,5 до 7,5 \%, реакция среды Рнкс составляет 5,5-6,0, обеспеченность нитратным азотом низкая (4,0-8,0 мг/кг), подвижным фосфором - высокая (170,0-180,0 мг/кг) и обменным калием повышенная и высокая $(110,0$ $140,0 \mathrm{mr} / \mathrm{kr})$.

При расчете баланса растительных остатков использовали статистические данные по уро- жайности сельскохозяйственных культур за 2016-2018 гг. Учет баланса растительных остатков полевых культур определяли в соответствии с принятыми рекомендациями [6].

Для расчета выноса питательных веществ сельскохозяйственными культурами использовали принятые в агрохимической службе рекомендации [7]. Коэффициенты пересчета растительных остатков в навоз, гумус, макроэлементы взяты из методических указаний МСХ РФ [9].

Результаты и их обсуждение. В учхозе «Миндерлинское» в последние годы в полевых и кормовых севооборотах выращивают зерновые, зернобобовые, пропашные культуры и кормовые травы (табл. 1).

Урожайность сельскохозяйственных культур в годы наблюдений была неодинаковой. Она зависела от плодородия почв, обеспеченности их подвижными формами элементов минерального питания, погодных условий, сортовых особенностей полевых культур, технологии выращивания и уровня применения минеральных удобрений. Наиболее высокие урожаи зерновых культур отмечаются в 2018 году. Среди зерновых культур самый высокий урожай зерна был получен у овса. У этой культуры в сравнении с 2016 годом урожайность зерна увеличилась в 1,9 раза. У яровой пшеницы и ячменя в 2018 году урожайность зерна в 1,2-1,6 раза была выше, чем в 2016 году.

\section{Урожайность сельскохозяйственных культур в учхозе «Миндерлинское»}

Таблица 1

$$
\text { (2016-2018 гг.), т/га }
$$

\begin{tabular}{|c|c|c|c|c|}
\hline \multirow{2}{*}{ Культура } & \multicolumn{3}{|c|}{ Год } & \multirow{2}{*}{$\begin{array}{c}\text { Среднее за } 3 \\
\text { года }\end{array}$} \\
\hline & 2016 & 2017 & 2018 & \\
\hline $\begin{array}{l}\text { Яровая пшеница } \\
\text { (Новосибирская 15) }\end{array}$ & 2,45 & 2,69 & 3,0 & 2,71 \\
\hline Ячмень (Ача) & 2,00 & 2,59 & 3,13 & 2,57 \\
\hline Овес (Саян) & 2,30 & 2,30 & 4,44 & 3,01 \\
\hline Горох (Радомир) & - & 2,50 & 1.60 & 1,37 \\
\hline Соя (Заряница) & - & - & 0,66 & 0,66 \\
\hline Картофель (Гала, Арамис) & - & - & 14,05 & 4,68 \\
\hline $\begin{array}{l}\text { Однолетние травы } \\
\text { на зеленую массу (горох+ } \\
\text { овес+ячмень+пшеница) }\end{array}$ & 6,50 & 7,30 & 8,50 & 7,43 \\
\hline $\begin{array}{l}\text { Многолетние травы } \\
\text { (кострец безостый на сено) }\end{array}$ & 1,45 & 1,31 & 1,00 & 1,25 \\
\hline
\end{tabular}


Увеличение урожайности зерновых культур в хозяйстве произошло за счет использования новых интенсивных сортов этих культур, увеличения применения доз минеральных удобрений и количества атмоссрерных осадков, выпавших за вегетационный период растений. В то же время урожайность сои, однолетних и многолетних трав на сено была невысокой. Это связано с биологическими особенностями развития растений сои и низким уровнем применения минеральных удобрений при возделывании однолетних и многолетних трав.
Поступление растительных остатков полевых культур в почву зависело от их урожайности, технологии возделывания и использования в животноводстве, когда у кормовых трав надземная часть отчуждается (табл. 2).

Наибольшее количество растительных остатков поступает в почву после уборки урожая зерновых культур. Среди этих культур больше всего биомассы растений заделывалось в почву при возделывании овса и яровой пшеницы.

Таблица 2

\section{Примерные ресурсы растительных остатков сельскохозяйственных культур в учхозе «Миндерлинское» (в среднем 3а 2016-2018 гг.). т/га}

\begin{tabular}{|l|c|c|c|c|}
\hline \multirow{2}{*}{ Культура } & \multicolumn{4}{|c|}{ Биомасса } \\
\cline { 2 - 5 } & $\begin{array}{c}\text { Побочная } \\
\text { продукция }\end{array}$ & $\begin{array}{c}\text { Поверхностные } \\
\text { остатки }\end{array}$ & Корни & Всего \\
\hline Яровая пшеница & 3,33 & 1,08 & 2,75 & 7,16 \\
\hline Ячмень & 3,01 & 0,99 & 2,40 & 6,40 \\
\hline Овес & 3,73 & 1,05 & 2,80 & 7,58 \\
\hline Горох & 1,94 & 0.41 & 1,34 & 3.69 \\
\hline Соя & 1,31 & 0,44 & 1,18 & 2,93 \\
\hline Картофрель & 0.63 & 0,22 & 0,51 & 1,36 \\
\hline Однолетние травы & - & 0,92 & 2,52 & 3,44 \\
\hline Многолетние травы & - & 0.85 & 2,10 & 2,95 \\
\hline Среднее по хозяйству & 1,74 & 0,74 & 1,94 & 4,42 \\
\hline
\end{tabular}

В среднем после уборки яровой пшеницы, овса и ячменя в почву поступает в 2,2 раза больше растительных остатков в сравнении с однолетними и многолетними травами. Это объясняется тем, что основная надземная выращиваемая продукция полностью используется на корм сельскохозяйственным животным. Наименьшее количество побочной продукции, поверхностных и корневых остатков поступает в почву после уборки гороха, сои и картофеля, так как эти культуры выращивались в хозяйстве только в 2018 году. В среднем после уборки урожая сельскохозяйственных культур в почву поступает 4,42 т/га растительных остатков.

Оптимизация гумусного состояния почвы важнейшее условие интенсификации земледелия и повышения урожайности сельскохозяйст- венных культур. В агроценозах Красноярского края отмечается отрицательный баланс гумуса [1]. Уменьшение содержания гумуса в почвах связано с недостаточным уровнем применения органических удобрений, развития эрозионных процессов, увеличением площади паров, подпахиванием нижележащих горизонтов, несовершенством технологии выращивания сельскохозяйственных культур. Для стабилизации гумусного состояния почв необходимо шире использовать на удобрение растительные остатки различных полевых культур.

В учхозе «Миндерлинское» наибольшее количество новообразованного гумуса поступает в почву при запахивании в нее растительных остатков зерновых культур (табл. 3). 
Примерное поступление гумуса и питательных веществ в почву при запахивании Таблица 3 растительных остатков (среднее за 2016-2018 гг.)

\begin{tabular}{|c|c|c|c|c|c|c|c|}
\hline \multirow[b]{2}{*}{ Культура } & \multirow{2}{*}{$\begin{array}{c}\text { Среднее количество } \\
\text { растительных } \\
\text { остатков, т/га }\end{array}$} & \multirow{2}{*}{$\begin{array}{l}\text { Эквивалент } \\
\text { навозу, т/га }\end{array}$} & \multirow{2}{*}{$\begin{array}{c}\text { Гумус, } \\
\text { т/га }\end{array}$} & \multicolumn{4}{|c|}{ Питательные вещества, кг/га } \\
\hline & & & & $\mathrm{N}$ & $\mathrm{P}_{2} \mathrm{O}_{5}$ & $\mathrm{~K}_{2} \mathrm{O}$ & Всего \\
\hline $\begin{array}{l}\text { Яровая } \\
\text { пшеница }\end{array}$ & 7,16 & 3,58 & 0,72 & 17,9 & 8,9 & 21,5 & 48,3 \\
\hline Ячмень & 6,40 & 3,20 & 0,64 & 16,0 & 8,0 & 19,2 & 43,2 \\
\hline Oвес & 7,58 & 3,79 & 0,76 & 18,9 & 9,5 & 22,7 & 51,1 \\
\hline Горох & 3,69 & 1,85 & 0,37 & 9,2 & 4,6 & 11,1 & 24,9 \\
\hline Соя & 2,93 & 1,46 & 0,43 & 7,3 & 3,6 & 8,6 & 19,5 \\
\hline Картофель & 1,36 & 0,68 & 0,14 & 3,4 & 1,7 & 4,1 & 9,2 \\
\hline $\begin{array}{l}\text { Однолетние } \\
\text { травы }\end{array}$ & 3,44 & 1,72 & 0,34 & 8,6 & 4,3 & 10,3 & 23,2 \\
\hline $\begin{array}{l}\text { Многолетние } \\
\text { травы }\end{array}$ & 2,95 & 1,48 & 0,30 & 7,4 & 3,7 & 8,9 & 20,09 \\
\hline $\begin{array}{l}\text { Среднее по } \\
\text { хозяйству }\end{array}$ & 4,43 & 2,22 & 0,46 & 11,1 & 5,5 & 13,3 & 29,9 \\
\hline
\end{tabular}

С растительными остатками яровой пшеницы, ячменя и овса в почве образуется в 2,2 раза больше гумусовых веществ в сравнении с однолетними и многолетними травами. Наименьшее количество гумуса поступает в почву с растительными остатками сои и картофеля. В среднем при запахивании растительных остатков всех сельскохозяйственных культур в почвы хозяйства поступает 0,46 т/га гумуса.

Растительные остатки содержат большое количество питательных веществ, которые доступны для питания растений после минерализации органического вещества. Количество поступающих в почву азота, фосфора и калия биомассы растений зависит от типа севооборотов, плодородия почв, уровня применения удобрений, урожайности и биологических особенностей полевых культур. Среди разных культур наибольшее количество питательных веществ поступает в почву с растительными остатками овса и яровой пшеницы и наименьшее с зернобобовыми культурами. Это обусловлено низкой урожайностью последних. С растительными остатками кормовых трав в почву возвращается в 2,2 раза меньше питательных веществ в сравнении с зерновыми культурами, что связано с отчуждением надземной части растений для кормления сельскохозяйственных животных. В среднем по хозяйству с растительными остатками полевых культур в почву поступает 29,9 кг/га азота, фосфрора и калия.

При расчете компенсации учитывают средний вынос питательных веществ урожаями сельскохозяйственных культур и их возврат с растительными остатками (табл. 4).

Вынос питательных веществ растениями происходит в зависимости от погодных условий, типа почв и обеспеченности их питательными веществами, внесенных удобрений, биологических особенностей культур, величины и структуры полученного урожая. Сельскохозяйственные растения в одинаковых условиях произрастания выносят различное количество питательных веществ, которое в значительной степени зависит от их сортовых особенностей. Величина выноса питательных веществ растениями не может считаться постоянной. Использование новых приемов агротехники, внедрение современных интенсивных сортов позволяют формировать урожаи сельскохозяйственных культур с меньшим расходом того или иного элемента питания.

Выращиваемые в учхозе сельскохозяйственные культуры характеризуются неодинаковым выносом питательных веществ. На показатели выноса элементов питания на разных отделениях хозяйства оказывают влияние плодородие почв, влагообеспеченность растений в течение 
вегетационного периода, сортовые особенности и уровень применения удобрений.

Среди разных культур наибольшее количество азота, фосффора и калия выносится с урожаем яровой пшеницы. Несколько меньше питательных веществ потребляется урожаями овса и ячменя. В группе зернобобовых культур больше макроэлементов выносится урожаем гороха. В кормовых севооборотах много питательных веществ выносят многолетние травы. Наименьшее количество питательных веществ в хозяйстве потребляют картофель и соя. В среднем по хозяйству с урожаями разных культур из почвы выносится 127,8 кг/га азота, фосфора и калия.

Таблица 4

Компенсация выноса питательных веществ урожаями сельскохозяйственных культур при использовании на удобрение растительных остатков (среднее за 2016-2018 гг.)

\begin{tabular}{|c|c|c|c|c|c|c|c|c|c|c|c|c|}
\hline \multirow[t]{2}{*}{ Культура } & \multicolumn{4}{|c|}{$\begin{array}{c}\text { Средний вынос полевыми } \\
\text { культурами, кг/га }\end{array}$} & \multicolumn{4}{|c|}{$\begin{array}{c}\text { Возврат питательных } \\
\text { веществ с растительными } \\
\text { остатками, кг/га }\end{array}$} & \multicolumn{4}{|c|}{$\begin{array}{c}\text { Компенсация выноса } \\
\text { за счет внесения в почву } \\
\text { растительных остатков, \% }\end{array}$} \\
\hline & $\mathrm{N}$ & $\mathrm{P}_{2} \mathrm{O}_{5}$ & $\mathrm{~K}_{2} \mathrm{O}$ & Всего & $\mathrm{N}$ & $\mathrm{P}_{2} \mathrm{O}_{5}$ & $\mathrm{~K}_{2} \mathrm{O}$ & Всего & $\mathrm{N}$ & $\mathrm{P}_{2} \mathrm{O}_{5}$ & $\mathrm{~K}_{2} \mathrm{O}$ & Всего \\
\hline $\begin{array}{l}\text { Яровая } \\
\text { пшеница }\end{array}$ & 108,4 & 94,8 & 73,2 & 276,4 & 17,9 & 8,9 & 21,5 & 48,3 & 16,5 & 9,4 & 29,4 & 18,4 \\
\hline Ячмень & 74,5 & 61,7 & 51,4 & 187,6 & 16,0 & 8,0 & 19,2 & 43,2 & 21,4 & 12,9 & 37,3 & 23,8 \\
\hline Овес & 84,3 & 66,2 & 63,2 & 213,7 & 18,9 & 9,5 & 22,7 & 51,1 & 22,4 & 14,3 & 36,0 & 24,2 \\
\hline Горох & 26,0 & 41,1 & 31,5 & 98,6 & 9,2 & 4,6 & 11,1 & 24,9 & 35,3 & 11,2 & 35,2 & 27,2 \\
\hline Соя & 8,5 & 19,8 & 15,2 & 43,5 & 7,3 & 3,6 & 8,6 & 19,5 & 85,9 & 18,2 & 56,6 & 53,6 \\
\hline Картофель & 18,2 & 22,0 & 19,6 & 59,8 & 3,4 & 1,7 & 4,1 & 9,2 & 18,7 & 7,7 & 20,9 & 15,7 \\
\hline $\begin{array}{l}\text { Однолетние } \\
\text { травы (3/м) }\end{array}$ & 22,3 & 18,6 & 20,8 & 61,2 & 8,6 & 4,3 & 10,3 & 23,2 & 38,6 & 23,1 & 49,5 & 37,1 \\
\hline $\begin{array}{l}\text { Многолетние } \\
\text { травы (сено) }\end{array}$ & 33,7 & 23,7 & 23,7 & 81,1 & 7,4 & 3,7 & 8,9 & 20,0 & 21,9 & 15,6 & 37,5 & 25,0 \\
\hline $\begin{array}{l}\text { Среднее по } \\
\text { хозяйству }\end{array}$ & 47,0 & 43,5 & 37,3 & 127,8 & 11,1 & 5,5 & 13,3 & 29,9 & 32,6 & 14,0 & 37,8 & 28,1 \\
\hline
\end{tabular}

Возврат питательных веществ в почву зависит от величины урожая сельскохозяйственных культур и химического состава растений. Наибольшее количество азота, фосфрора и калия возвращается в почву с растительными остатками овса и яровой пшеницы. Много питательных веществ поступает в почву при запахивании растительных остатков зернобобовых культур и кормовых трав. В среднем по хозяйству суммарное поступление питательных веществ с растительными остатками составляет 29,9 кг/га. В полевых и кормовых севооборотах наибольшая компенсация выноса питательных веществ с урожаями отмечается по зернобобовым культурам и однолетним травам.

Выводы. В среднем по хозяйству компенсация выноса урожаями культур за счет внесения в почву растительных остатков в качестве органических удобрений для азота составляет $32,6 \%$, фоссрора - 14,0 и калия 37,8 \%.
Особенности накопления и химический состав растительных остатков необходимо учитывать при разработке системы удобрения, оценке и прогнозе экологического состояния земель.

\section{Литература}

1. Алхименко Р.В. Мониторинг состояния пахотных земель в Западном и Центральном территориальных округах Красноярского края // Достижения науки и техники АПК. 2017. T. 31. № 6. C. 11-14.

2. Волошин Е.И., Ивченко В.К., Рудой Н.Г. Биологические ресурсы минерального питания сельскохозяйственных культур в Красноярском крае // Вестник КрасГАУ. 2018. № 6. C. 51-56.

3. Волошин Е.И., Рудой Н.Г. Особенности накопления растительных остатков полевых 
культур в Средней Сибири // Вестник КрасГАУ. 2019. № 2. С. 3-10.

4. Кирюшин В.И. Управление плодородием почв и продуктивностью агроценозов в адаптивно-ландшафртных системах земледелия // Почвоведение. 2019. № 39. C. $1130-1139$.

5. Лыков А.М., Еськов А.И., Новиков М.Н. Органическое вещество пахотных почв Нечерноземья (актуальность и состояние проблемы, рабочие гипотезы исследований, сопряженность агрономических и экологических функций, динамика в агроценозах, принципы моделирования и технологии воспроизводства). М.: РоссельхозакадемияГНУ ВНИПТИОУ, 2004. 630 с.

6. Рекомендации для исследования баланса и трансформации органического вещества при сельскохозяйственном использовании / отв. ред Л.Л. Шишов. М.. 1984. 96 с.

7. Рекомендации по определению доз минеральных удобрений под сельскохозяйственные кульутры на планируемый урожай. Красноярск, 1987. 24 с.

8. Семенов В.М., Ходжаева А.К. Агрономические функции растительных остатков в почве // Агрохимия. 2006. № 7. С. 68-81.

9. Составление проекта на применение удобрений: рекомендации. М.: ФГНУ «Росинформагротех», 2000. $155 \mathrm{c}$.

\section{Literatura}

1. Alhimenko R.V. Monitoring sostojanija pahotnyh zemel' v Zapadnom i Central'nom territorial'nyh okrugah Krasnojarskogo kraja /I Dostizhenija nauki i tehniki APK. 2017. T. 31. № 6. S. 11-14.
2. Voloshin E.I., Ivchenko V.K., Rudoj N.G. Biologicheskie resursy mineral'nogo pitanija sel'skohozjajstvennyh kul'tur v Krasnojarskom krae // Vestnik KrasGAU. 2018. № 6. S. 51-56.

3. Voloshin E.I., Rudoj N.G. Osobennosti nakoplenija rastitel'nyh ostatkov polevyh kul'tur v Srednej Sibiri // Vestnik KrasGAU. 2019. № 2. S. 3-10.

4. Kirjushin V.I. Upravlenie plodorodiem pochv i produktivnost'ju agrocenozov $\mathrm{v}$ adaptivnolandshaftnyh sistemah zemledelija /I Pochvovedenie. 2019. № 39. S. 1130-1139.

5. Lykov A.M., Es'kov A.I., Novikov M.N. Organicheskoe veshhestvo pahotnyh pochv Nechernozem'ja (aktual'nost' i sostojanie problemy, rabochie gipotezy issledovanij, soprjazhennost' agronomicheskih i jekologicheskih funkcij, dinamika $v$ agrocenozah, principy modelirovanija i tehnologii vosproizvodstva). M.: Rossel'hozakademija-GNU VNIPTIOU, 2004. $630 \mathrm{~s}$.

6. Rekomendacii dlja issledovanija balansa i transformacii organicheskogo veshhestva pri sel'skohozjajstvennom ispol'zovanii / otv. red L.L. Shishov. M.. 1984. $96 \mathrm{~s}$.

7. Rekomendacii po opredeleniju doz mineral'nyh udobrenij pod sel'skohozjajstvennye kul'utry na planiruemyj urozhaj. Krasnojarsk, 1987. 24 s.

8. Semenov V.M., Hodzhaeva A.K. Agronomicheskie funkcii rastitel'nyh ostatkov v pochve // Agrohimija. 2006. № 7. S. 68-81.

9. Sostavlenie proekta na primenenie udobrenij: rekomendacii. M.: FGNU «Rosinformagroteh», 2000. $155 \mathrm{~s}$. 